\title{
ESTUDO DOS MODOS DE PRODUÇÃO DE JUSTIÇA DA LEI MARIA DA PENHA EM SANTA CATARINA
}

\author{
Regina Ingrid Bragagnolo \\ Universidade Federal de Santa Catarina \\ Mara Coelho de Souza Lago \\ Universidade Federal de Santa Catarina \\ Theophilos Rifiotis \\ Universidade Federal de Santa Catarina
}

\begin{abstract}
Resumo: Esse artigo objetiva descrever as práticas da justiça criminal construídas a partir da Lei 11.340/2006, Lei Maria da Penha, por juízes e juízas encarregados/as da aplicação deste dispositivo legal em uma Vara Criminal e Juizado de Violência contra a Mulher, em Santa Catarina. Trata-se de um estudo de inspiração etnográfica, que utilizou como fonte de pesquisa entrevistas com operadoras/os do direito e diários de campo, construídos a partir de observação de audiências e análise documental de processos penais. A pesquisa mostrou que as práticas rotineiras das/os operadoras/es do direito, no tratamento jurídico de casos tipificados como de "violência doméstica e familiar contra a mulher", estavam orientadas pelos "estilos" pessoais de cada magistrado/a ao conduzir as audiências de ratificação, caracterizando formas de comunicação e interação de acordo com valores morais, marcados por diferentes concepções de gênero, família e justiça. A observação das práticas de equacionamento e julgamento evidenciou que os modos de produção de justiça estavam aliados à dimensão moral, de certa forma velada nos discursos dos/as operadores/as do direito, ao fazerem uso dos códigos legais. As posições políticas dessas/es profissionais, acerca do processo de criminalização da "violência doméstica e familiar contra a mulher", resultaram, muitas vezes, em práticas contrárias às expectativas dos movimentos feministas com a criação da Lei Maria da Penha, mostrando a importância do debate sobre a judicialização das relações sociais no campo dos estudos de gênero.

Palavras-chave: Lei Maria da Penha; operadores e operadoras do direito; justiça; violência de gênero.
\end{abstract}

Copyright $\odot 2015$ by Revista Estudos Feministas. 


\section{Introdução}

O presente artigo procura somar-se aos esforços de reflexão sobre a produção da justiça no campo dos estudos de gênero, ao qual se dedicaram importantes pesquisadoras brasileiras, ' discutindo as mudanças conceituais e operacionais da "violência de gênero" no cenário nacional e destacando, além de outros aspectos, o tratamento da problemática na esfera do direito e da justiça criminal. Citando o livro, organizado mais recentemente por Carmen Hein de Campos, ${ }^{2}$ Lei Maria da Penha comentada em uma perspectiva jurídicofeminista, aqui procuramos dar continuidade aos trabalhos que pretendem desenvolver uma reflexão crítica da judicialização das relações sociais no campo do gênero. ${ }^{3}$

O debate em torno da "aposta política" que os movimentos sociais têm realizado ao eleger os ordenamentos jurídicos como uma estratégia central no combate à "violência doméstica e familiar contra a mulher", ${ }^{4}$ coloca em pauta a necessidade de monitorar as estratégias que as/os operadoras/es do direito utilizam na aplicação da Lei Maria da Penha (LMP). ${ }^{5}$ Assim, o presente artigo descreve as práticas de operadoras/os do direito no atendimento às demandas oriundas da Lei $11.340 / 2006,{ }^{\circ}$ cuja origem está ligada a fenômenos sociopolíticos, tanto nas lutas dos movimentos feministas brasileiros pela tipificação da "violência doméstica e familiar contra a mulher" como crime passível de penalização e de políticas de prevenção, quanto de expansão do direito, em particular do direito penal, e do acesso à justiça. ${ }^{7}$

Em linhas gerais, procuramos no presente trabalho situar os modos de produção de justiça construídos a partir da LMP pelas/as operadoras/os do direito encarregadas/os de sua aplicação, tomando como material empírico a pesquisa realizada numa Vara Criminal da Região Metropolitana de Florianópolis, no período de 2008 a 2010. ${ }^{8}$ Importante ressaltar que na época não haviam sido criados os Juizados de Violência Doméstica e Familiar contra a Mulher em Santa Catarina, razão dos processos serem julgados em uma Vara Criminal. Apresentamos resultados de uma pesquisa qualitativa de inspiração etnográfica, envolvendo, portanto, observação direta e participante, registros em diários de campo e entrevistas, secundados por análise documental de processos jurídicos referidos a casos

\footnotetext{
' Conferir Mariza CORRÊA, 1983; Heleieth SAFFIOTI, 2004; Danielle ARDAILLON e Guita Grin DEBERT, 1987; DEBERT, 2006; Maria Filomena GREGORI, 1993; Miriam Pillar GROSSI, 1998; GROSSI, Luzinete Simões MINELLA e Juliana Cavilha Mendes LOSSO, 2006; Lourdes BANDEIRA e Mireya SUÁREZ, 1999; Eva Alterman BLAY, 2008; Márcia Queiroz de C. GOMES, Márcia Santana TAVARES e Cecília Bacellar SARDENBERG, 2010, entre muitas outras.

${ }^{2}$ Carmen Hein de CAMPOS, 2011.

${ }^{3}$ Theophilos RIFIOTIS, 2008, 2011, 2012, 2014a e 2014b.

${ }^{4}$ As autoras e o autor deste artigo, considerando os limites e as ambiguidades envolvidos na utilização da noção de "violência", que, conforme RIFIOTIS, 2008, é uma categoria descritivo-qualificadora, optam por manter ao longo do texto a expressão "violência doméstica e familiar" tal como está na LPM, e "violência de gênero" para falar da categoria analítica numa aproximação feminista.

${ }^{5}$ Aqui cabe uma observação geral sobre a centralidade do campo normativo nas lutas sociais que, se por um Iado, conforme RIFIOTIS, 2014a, é vetor de acesso à justiça, de visibilidade social, de reconhecimento e de promoção da equidade, por outro, afirma uma forma de politização da justiça baseada nos direitos dos sujeitos. Assim, a própria "politização da justiça" em termos do reconhecimento de que instituições como a Delegacia da Mulher e, mais recentemente, a Lei Maria da Penha são expressões de lutas sociais no sentido de promoção do acesso à justiça e da agenda igualitária feminista (DEBERT e GREGORI, 2008). "Trata-se da conquista de 'ganhos jurídicos' e da 'aposta' numa potência transformadora da normatividade e no sistema de justiça criminal" (RIFIOTIS, 2014a, p. 16).

${ }^{6}$ BRASIL, 2006.

7 RIFIOTIS, 2008 e 2012.

${ }^{8}$ Realizada como pesquisa de doutoramento por uma das autoras desse texto (Regina BRAGAGNOLO, 2012) em um Tribunal de Justiça de um dos nove municípios da Região Metropolitana estudada.
} 
observados em audiências. As entrevistas foram realizadas com cinco juízes e três juízas, com idades entre 37 e 50 anos, além de outras/os operadoras/os do direito.

Entre 2008 e 2010, a economia de trabalho na Vara Criminal estudada estava organizada a partir da decisão do Superior Tribunal de Justiça, tornando a "audiência de ratificação" a porta de entrada no Judiciário para os casos tipificados no âmbito da "violência doméstica e familiar". ${ }^{9}$ Essa modalidade de audiência foi criada para atender a necessidade de "representação" da mulher, já que os outros procedimentos e as sessões de audiências seguiam o mesmo rito e processamento das demais ações penais. No plano formal, a ação penal era considerada "condicionada à representação" da mulher, entretanto, na observação do fluxo dos processos referentes a LMP, percebemos que, no período da pesquisa, o conjunto das relações estabelecidas dentro e fora das "audiências de ratificação" era fundamental para a continuidade ou interrupção do processo, resultando numa dinâmica inicial de triagem dos casos que chegavam ao Judiciário e, por conseguinte, no afunilamento dos processos penais. Observamos na pesquisa que muitos processos não chegavam a julgamento, sendo extintos não mais nas Delegacias Especializadas em Atendimento à Mulher (DEAMs) e nos Juizados Especiais Criminais (JECrims) ${ }^{10}$ como acontecia antes da homologação da Lei 11.340, mas na própria Vara Criminal onde tramitavam. Ainda que num momento inicial da implantação da Lei 11.340 , e anterior à decisão do STF de 2012, tornando os casos de "violência doméstica e familiar contra a mulher" ações incondicionadas, a prática das "audiências de ratificação", que foi nosso objeto específico de análise no presente texto, mostra características do modo de produção de justiça no campo do gênero que merecem ser debatidas porque talvez sejam mais recorrentes do que se poderia prever.

No nosso entendimento, dada a complexidade da judicialização da "violência de gênero", é da maior importância a multiplicação de estudos etnográficos que forneçam elementos concretos sobre as práticas de produção de justiça. Foi o que procuramos fazer, concentrando-nos aqui nas figuras do juiz e da juíza e destacando os distintos modos de proceder e avaliar os casos de "violência doméstica e familiar", especificamente no âmbito das "audiências de ratificação". A seguir apresentamos uma síntese dos resultados da pesquisa que permitem uma reflexão crítica sobre os modos de produção da justiça em audiências de ratificação nos casos de "violência doméstica e familiar".

\section{Modos de produção da justiça e "estilos" de julgar nas audiências de ratificação}

Desde o início do trabalho de campo foi recorrente ouvir dos/as operadores/as do direito considerações sobre o modo como atuava cada magistrado/a, como se identificassem uma espécie de "estilo" de julgar. O que foi confirmado pela observação direta nas audiências de ratificação e nas entrevistas com os/as magistrados/as. A relação entre "estilos" e os resultados dos processos encaminhados para a Vara onde foi realizada a pesquisa são o centro do presente artigo. Serão apresentados três "estilos" que identificamos na nossa pesquisa, os quais chamaremos de "tutelar", "arbitral" e de "reparação moral".

\footnotetext{
${ }^{9}$ Lembramos que somente em 2012 o Supremo Tribunal Federal define que a Lei 11.340/2006 é de ação penal pública incondicionada.

${ }^{10} \mathrm{Na}$ Lei $9.099 / 95$ (BRASIL, 1995), o encaminhamento da ação estava atrelado ao Termo Circunstanciado, que remetia o processo para o JECrim, resultando, em geral, em acordos entre as partes e/ou pagamento de cestas básicas pelo acusado (DEBERT e Marcella BERALDO DE OLIVEIRA, 2007).
} 


\section{Estilo tulelar}

Desde a apresentação inicial em campo, soubemos que havia um "juiz feminista" na Vara Criminal estudada. Nos diálogos com os/as advogados/as perguntamos sobre as razões de tal atributo. Uma advogada afirmou que ele era reconhecido como estudioso da LMP: "Ele é o juiz que mais conhece e defende a Lei Maria da Penha nessa comarca, inclusive já foi palestrante na universidade e esteve dando entrevista na televisão e no jornal." Mas será que todo homem estudioso da LMP naquele Tribunal de Justiça seria considerado feminista? Provavelmente, o juiz era associado a essa representação por seu posicionamento favorável à Lei, mas qual seria esse posicionamento e como ele se traduziria na sua prática?

Em ocasião em que acompanhávamos o advogado de um acusado, " este perguntou à estagiária quem estaria presidindo a audiência. A resposta o fez suspirar, afirmando: "Ah é, já sabia. Vou avisar ao meu cliente que ele deve só escutar e nada falar nessa audiência." E comentou: "Esse juiz é feminista [...] ele é o defensor das mulheres."

O fato desse juiz, o primeiro magistrado a assumir aquela Vara Criminal, ser considerado um estudioso e defensor da LPM o distinguia, como também o fato de sua trajetória profissional estar marcada pelo reconhecimento de sua contribuição para a criação do Juizado no Tribunal de Justiça onde foi realizada a pesquisa. Nas audiências de ratificação presididas por ele, as impressões das/os advogadas/os ganharam forma concreta. Numa dessas audiências, após o juiz chegar à sua mesa, o estagiário convoca Samira ${ }^{12}$ para entrar na sala de audiência. Ela entra com o filho de aproximadamente dois anos em seu colo, acompanhada de uma profissional do direito (denominada pelos interlocutores de "advogada de plantão"13) que pergunta ao juiz se deve permanecer na audiência. Ela senta ao lado da mulher a quem se apresenta como advogada. Em seguida o juiz pergunta: "A senhora tem alguma objeção de prestar depoimento na frente de Paulo?"

Compreendemos posteriormente que essa pergunta inicial é uma prática recorrente, que poderia ser considerada com uma marca da atuação do juiz, uma espécie de "estilo" pessoal. Embora essa audiência tratasse de um caso específico, fazia parte dos encaminhamentos desse magistrado a pergunta inicial para as mulheres decidirem se desejavam, ou não, pronunciarem-se na presença do acusado.

No caso específico de Samira, ela declara que estaria disposta a depor na presença de Paulo e um estagiário de direito vai até a porta e o convida a entrar na sala. Após Paulo sentar-se no outro lado da mesa, a audiência inicia.

O juiz olha para Samira e explica: Esse procedimento é de ratificação. A pergunta é se você pretende reafirmar e dar continuidade no processo ou parar por aqui.

Samira: Ah, doutor, eu não sou a pessoa indicada [...]. É que ele é o pai do meu filho. Juiz: Eu entendo, mas você não tem receio de que ele volte a agredi-la? Ele melhorou cem por cento?

Samira: Ele veio pedindo desculpas e dizendo que quer voltar.

Juiz: Olha, dona Samira, eu conheço essa história, mas o que vejo é que eles não mudam, não. Só ficam na promessa.

\footnotetext{
11 Utilizamos o termo "acusado", por ser categoria corrente entre as/os operadoras/es do direito, junto à de "ofensor", para se referirem a homens que têm sobre si denúncia de agressão contra a companheira. A LMP faz referência a agressores e a ofensores, o que pode ser considerado como uma forma de reforçar a lógica binária homem-agressor, mulher-ofendida.

${ }^{12}$ Utilizamos em todo o texto nomes fictícios para preservar a identidade das/os interlocutores/as envolvidas/ os nos contextos analisados.
} 
Paulo: Doutor, é o seguinte. Houve uma briga...

O juiz o interrompe e continua o diálogo com Samira: Você está bem segura disso? Samira: Nós fomos no escritório modelo e decidimos lá. Ele é um bom pai, ajuda a cuidar o menino, eu acabei perdoando.

O juiz declara: Nesse caso, é melhor deixar de representar, e se acontecer novamente vai à delegacia. Mas se isso acontecer, vai correndo na delegacia, pois eles irão prendê-lo.

E continua falando, agora olhando diretamente para Paulo: $E$ aí você fica lá pensando um pouquinho. Ela é a mais frágil. Se você vê que a discussão está ficando calorosa, sai de casa; e se partir para a agressão, já sabe...

Paulo: Mas, doutor, agora é diferente.

O juiz interrompe: Paulo, essa audiência é para ouvir a mulher. Você foi chamado para ficar ciente das decisões aqui tomadas. Você não tem que falar. O que ela disser aqui é a verdade, eu acredito nela. E outra coisa importante: vocês têm um filho lindo. Essa criança percebe, escuta e sente quando vocês brigam. Eles são sensíveis.

Paulo insiste com o juiz: Posso conversar consigo rapidinho?

O juiz continua: Olha, ela tem o direito de parar por aqui. Ela já sabe que se ocorrer novamente, tem o direito garantido. A cada novo fato é um novo processo. E você tem que cuidar dessa criança com exemplo de harmonia, pois, se for o contrário, vai repercutir no comportamento dele.

Enquanto o juiz conversava com Paulo, a advogada falava paralelamente com Samira. Na sequência, o juiz explica que a medida protetiva não estará mais em vigor, e, enquanto eles assinam o termo da audiência, comenta com a advogada que designará OS URHs. ${ }^{14}$

A descrição da audiência explicita algumas características do "estilo" adotado por este juiz. A diversidade das situações alterava algumas vezes essas sessões, mas, frequentemente, havia, em relação a outras/os juízas/es, mais espaço para a mulher se pronunciar. As tentativas de manifestação dos homens, como ocorreu nesse caso, eram frequentes. Nesses casos, o acusado era interrompido pelo magistrado e, se insistisse, a reação do juiz era marcar/delimitar sua autoridade. Nessas situações, o juiz afirmava seu papel soberano na condução do rito, que correspondia a uma determinação de que nessas audiências as mulheres é que deveriam se pronunciar, uma vez que o objetivo da sessão era confirmar a representação da mulher. Se o processo continuasse, o acusado seria ouvido na audiência de instrução e julgamento, onde seria realizado interrogatório.

O lugar definido para o acusado nas audiências de ratificação era o de escuta; ele não devia falar, e sim ouvir os relatos da outra parte, e as prescrições do juiz, mescladas com orientações e ameaças. Na sessão de audiência apresentada, o homem ora ocupa o lugar de acusado, portanto, o de alguém que pode ter cometido um crime, ora o de pai, que tem deveres de proteger e tutelar seu filho. No início da audiência, Paulo é considerado

\footnotetext{
${ }^{13}$ Categoria utilizada pelas/os operadoras/es do direito para referir-se às/aos advogadas/os que permaneciam nos corredores do Tribunal de Justiça, aguardando uma audiência em que uma das partes não estivesse acompanhada por advogada/o. Era comum encontrar nas audiências de ratificação, principalmente, advogadas/os recém-formadas/os aguardando.

${ }^{14}$ Fazia parte do rito a designação da juíza ou do juiz aos chamados URHs (unidade referencial de honorários) para as/os advogadas/os da Assistência Judiciária. No fim da audiência, a juíza ou o juiz perguntava à/ao advogada/o sobre sua condição: "defensoria dativa" ou "nomeada/o". Quando a/o profissional era contratada/ o por uma das partes, tinha a designação de "nomeada/o". Nesta audiência específica, assim como na maior parte das vezes, a advogada prestou serviços pela Assistência Judiciária, por isso era considerada dativa.
} 
acusado e deve escutar algumas colocações do juiz, dentre as quais a possibilidade de sua detenção se houver reincidência da agressão. O juiz declara, energicamente, que a detenção poderia ser a medida adotada, caso a "violência doméstica e familiar" reincidisse, com a intenção de fazer o acusado refletir: "[...] você fique lá pensando um pouquinho. Ela é a mais frágil. Se você vê que a discussão está ficando calorosa, sai de casa; e se partir para a agressão, já sabe". Segundo o juiz afirmou posteriormente em conversa informal: "A intenção é que eles se sintam intimidados, aprendam com isso". A estratégia desse magistrado, ao intimidar, revela características da relação estabelecida com o acusado, cuja ênfase é uma conjunção de ameaça e discurso moralizador.

No decorrer da audiência, Paulo passa a ser reconhecido como pai, estatuto que o coloca em outra condição, devendo também ouvir as recomendações do juiz a respeito dos cuidados com seu filho. Fica evidente que o juiz deixa de questionar Samira sobre o prosseguimento da ação penal no momento em que ela descreve que Paulo é um "bom pai". O magistrado, ainda se referindo a esta questão em outro momento, afirmou: "Em briga de marido e mulher ninguém mete a colher, vírgula, quando tem filho é diferente! $O$ Estado tem a obrigação de intervir quando o caso envolve filhos".

Esta questão, somada às recomendações do juiz sobre o cuidado com o filho, é chave para a compreensão da concepção de mulher, casamento e família que as/os operadoras/es do direito evidenciam nessas audiências. Neste sentido, a pesquisa de Mariza Corrêa ${ }^{15}$ oferece subsídios importantes para pensar as implicações de gênero nas práticas jurídicas. Aqui, em específico, é possível considerar que a representação masculina parece estar assentada nos traços adjetivos do bom pai de família, trabalhador e provedor. Tais valores persistem no imaginário social e atravessam as concepções e práticas concretas de juristas. E ainda, nessa formulação de raciocínio que valida a intervenção jurídica, transparece na narrativa do magistrado a concepção de que sua mediação pode produzir consequências práticas no contexto social dos sujeitos envolvidos no processo, conforme explicitou esse juiz em sua entrevista:

Com certeza houve mudança, não apenas pelo acréscimo de trabalho, pois são medidas protetivas que demandam pronto atendimento, mas também pelo fato de se tratar de inovação no nosso ordenamento jurídico. E aí está a grande presteza da nova Lei. O juiz delibera essas questões e coloca 'equilíbrio no casal', afastando um e deixando o outro na decisão da separação judicial ou consensual. (Juiz, 52 anos)

A intenção de possibilitar "equilíbrio no casal" durante o processo na justiça criminal parece-nos revelar certa pretensão do juiz em mediar/deliberar as regras de relacionamento a partir das prescrições legais dentro da lógica técnico-jurídica. Dito de outra forma, a solução que o juiz encontra para "equilibrar o casal" pode parecer, num primeiro momento, uma prática de conciliação. No entanto, seu argumento revela uma determinação, uma prescrição, pois essa é uma "mulher frágil", que necessita da intervenção do profissional juiz para modificar sua trajetória de vida. O fato de a mulher ser apresentada como frágil torna possível a tarefa do juiz de submetê-la à sua determinação, que vai incidir de maneira específica na exigência de que ela entre com a ação de separação na Vara Cível.

Aqui vale retomar as representações ligadas ao juiz "feminista", pois para as/os operadoras/es do direito ele representa um defensor da mulher, e esta questão a nosso ver está atrelada a representações generificadas, sendo as mulheres consideradas por ele como "frágeis". A representação da mulher fragilizada permite que algumas/alguns magistradas/os entendam que sua função é de tutela, o que fica explícito em entrevista realizada com outro juiz:

15 CORRÊA, 1981. 
Aqui está o grande lance da lei: antes tínhamos o homem e 'a mulher fraquinha'. 0 homem usava a força física, mais o aspecto cultural, tudo isso fazia com que ele agredisse a mulher. Só que agora, hoje, o homem continua com sua força, a mulher continua do mesmo jeito, mas ela tem o Estado por trás dela. O Estado é o policial, o juiz, a estrutura toda. O que mudou realmente foi que você igualou a mulher colocando o Estado ao seu trabalho. Então se antes ela não podia enfrentar o marido sozinha, agora ela conta com a ajuda 'do delegado, do juiz, do promotor'. A medida protetiva é justamente para isso, para cessar a agressão e dar um 'opa, calma lá, você vai se entender com o mais forte, com o juiz, o promotor, o delegado'. Aqui é que está o xis da questão [...]. (Juiz, 48 anos)

Durante a entrevista esse juiz, enquanto falava, ia ilustrando por meio de desenho, a figura do homem considerado forte de um lado e, do outro, o Estado representado pelas/os operadoras/es do direito, ambos do mesmo tamanho; no meio, desenhou uma mulher com a metade do tamanho dos demais. As análises de Jacqueline Hermann e Leila Linhares Barsted e de Miriam Pillar Grossi e Analba Brazão Teixeira, ${ }^{16}$ descrevem como a diferença entre os sexos é transformada em desigualdade social na cultura jurídica. A narrativa exposta evidencia as formas como o Poder Judiciário incorpora a dicotomia e as assimetrias de gênero. A representação da passividade feminina, atrelada ao discurso das mulheres a partir da sua posição de vítima, presente na cultura jurídica, é traduzida no rito jurídico, especificamente quando nesta prática a concepção de mulher reproduz uma lógica sexista. ${ }^{17}$

Na complexidade de saberes envolvidos nas audiências de ratificação, destacamos que, apesar de as/os operadoras/es do direito evidenciarem a intenção de proteção da mulher, traduzida pela tutela estatal, esse princípio pode ser acompanhado pela concepção de "cidadania malograda". ${ }^{18}$ Ainda que essa discussão seja anterior à Lei 11.340, parece-nos que, na concepção das/os operadoras/es do direito, a mulher em "situação de violência doméstica e familiar" representa um sujeito incapaz, uma cidadania malograda na medida em que precisa ser tutelada, em contraposição à sua representação como um sujeito ativo que interage e organiza suas ações no mundo.

\section{Estilo arbitral}

Seguindo a discussão sobre o modo como as audiências de ratificação estruturavamse, apresentamos a prática de uma das juízas cujas audiências foram acompanhadas durante a pesquisa de campo e com a qual realizamos entrevista. Uma das primeiras falas desta juíza que nos chamou atenção, e diz respeito à sua concepção de gênero, foi proferida no intervalo de uma audiência, no dia em que a conhecemos: "A gente é mulher, sente diferente; se fôssemos homens, teríamos outra forma de sentir e olhar". Ela evidencia certa essencialização das diferenças entre homens e mulheres, afirmando uma diferença (natural) entre juízes e juízas no atendimento de mulheres em "situação de violência doméstica e familiar", que as inibiria ao terem que falar para um juiz homem sobre algumas questões. Há, de acordo com ela, dois elementos que diferem no seu atendimento a mulheres com histórico de "violência doméstica e familiar". Primeiro, o fato de ser mulher a coloca numa situação privilegiada para compreender o sofrimento de outras mulheres que chegam

\footnotetext{
16 Jacqueline HERMANN e Leila Linhares BARSTED, 1995; GROSSI e Analba Brazão TEIXEIRA, 2000.

${ }_{17}$ Alessandra de Andrade RINALDI, 2008.

${ }^{18}$ No atendimento policial realizado nas DEAMs, em décadas anteriores à homologação da LMP, eram caracterizadas concepções de incapacidade das partes em exercer sua cidadania, sendo reiterado o desempenho dos papéis na família (DEBERT, 2001, p. 1).
} 
para as audiências, ${ }^{19}$ segundo, e além disso, acredita que as mulheres sentem-se mais confortáveis quando atendidas por uma juíza.

Na audiência de Emile, após ser chamada pelo estagiário de direito, esta entra acompanhada da advogada. A juíza a cumprimenta e pergunta: "Podemos iniciar a audiência sem o André? Depois o chamamos, ok?" Fazia parte da sua prática convidar a mulher para iniciar a audiência e, após um diálogo breve sobre a continuidade ou não do processo, chamar o acusado. Do ponto de vista da juíza, a ação pública deveria ser incondicionada ${ }^{20}$ à representação da mulher. Sua posição contrária à ação condicionada à representação das mulheres foi evidenciada repetidamente nas audiências presididas por ela. Sua estratégia era mediar a decisão favorável à continuidade do processo junto às mulheres, para que pudesse ter seu consentimento.

Na sequência da audiência a juíza continua a perguntar a Emile:

Juíza: A senhora quer ratificar o processo?

Advogada: Ela não quer dar continuidade, doutora.

Juíza: Ele não incomodou mais? Não perturbou mais?

Emile: Agora voltou a trabalhar, fica ligando que quer voltar a morar junto e ver o Douglas [filho].

Advogada: Como eu já expliquei a você, no momento em que você não ratifica é arquivada a medida protetiva.

Juíza: Se o processo vai ser arquivado a medida protetiva não é mais vigente. Se tiver um novo fato e comunicar à delegacia, novo processo será instaurado.

Emile: Eu tenho medo dele, pois ele é militar e usa arma.

Juíza: Então você está me dizendo que se sente ameaçada?

A advogada continua: Doutora, o problema dela é que ele não aceita a separação. Enquanto está com medida protetiva ele está longe de casa.

Juíza: Estou vendo aqui no processo, você já teve muitos outros boletins de ocorrência, e essa não é a primeira vez que quer dar chance a ele. E tem adiantado?

Emile: Eu tenho medo, já bateu muito em mim na cabeça com a arma, e tenho medo que ele faça o que já me disse.

Juíza: Você tem condição de mudar de cidade?

Emile: Não, sou auxiliar de enfermagem, ganho pouco.

Juíza: Às vezes a melhor coisa é sair da cidade. Você mora de aluguel?

Emile: Não, não, a casa é nossa.

Juíza: Eu também não sei como ajudar, quando a gente quer paz. Do jeito que está a situação, você vai se incomodar. Não sei, mas talvez fique um ano fora.

O direcionamento da juíza permite pensar o lugar que Emile deve ocupar segundo as prescrições jurídicas, assim como as consequências desse encaminhamento na violação dos direitos fundamentais dessa mulher. Além disso, sob o argumento da reincidência da "violência", a juíza afirma o rumo que ela deve tomar. Essa direção permite pensar que, na concepção da juíza, o sistema jurídico não conta com instrumentos para proteção das mulheres, apesar de ser central na LMP o tópico das chamadas "medidas protetivas".

Uma das características das audiências presididas por essa juíza referia-se ao seu direcionamento para que a mulher aceitasse dar continuidade ao processo. Na sequência

19 Uma das contribuições feministas contemporâneas diz respeito à crítica a essa dicotomização, também presente na separação entre cultura e natureza (Mara Coelho de Souza LAGO, 2004), que inclui a desconstrução do essencialismo da categoria mulher/mulheres atrelada a uma identidade feminina universal (Donna HARAWAY, 1993).

${ }^{20}$ Vale destacar que essa questão foi evidenciada no período da pesquisa, mais precisamente em 2010 , no contexto social e político onde as decisões que tramitavam no STJ indicavam que a ação era condicionada à representação da mulher. 
do rito, a juíza chamava o acusado e dizia que ela, representante do Poder Judiciário, decidira, conjuntamente com a mulher "em situação de violência", pela continuidade do processo. "A gente decidiu que vai prosseguir com o processo".

Neste caso, estavam também em jogo o cumprimento da medida protetiva e a advertência ao acusado. A medida protetiva não era gerada a partir de um princípio universal - toda mulher em "situação de violência doméstica e familiar" diz a "verdade" -, mas da avaliação pessoal da juíza sobre um quadro de seu potencial descumprimento. Aliás, como pudemos perceber, o descumprimento de medida protetiva por parte dos acusados tendia a provocar uma reação forte e imediata em muitos dos juízes a cujas audiências assistimos, e não apenas nessa juíza. Contudo, no caso de Emile, o argumento do acusado, que descumpriu a medida protetiva, justificando o ato pelo desejo de estar com o filho, não redundou em penalização e ainda lhe garantiu o estabelecimento periódico de visitas ao menino.

Em suas decisões e seus encaminhamentos, esta juíza geralmente tratava também de questões atinentes à Vara Cível da Família e talvez ela incluísse essas questões em sua dinâmica de atendimento, por ter trabalhado por algum tempo nessa Vara Cível. O modo particular de lidar com essas demandas de família estava, assim, baseado em sua trajetória profissional, e está indicado na LPM no seu Artigo 33, referente à solução de questões civis/ familiares e penais em um mesmo juizado. Porém, quando o acusado justificou 0 descumprimento da medida protetiva, valendo-se da defesa do papel de pai provedor/ cuidador, esta passou a ser a tônica da audiência. A valoração do papel da família foi expressa nas falas: "[...] o direito de pai persiste. É prejudicial para a criança ficar longe dele", que caracterizam a preocupação com a manutenção da família, ${ }^{21}$ na medida em que reafirmam os lugares materno e paterno no cuidado com a prole.

A atitude da juíza, quando sugere que a mulher mude de cidade e logo em seguida justifica sua posição afirmando que não é possível protegê-la, contrapõe-se à lógica da tutela estatal ${ }^{22}$ estabelecida pelo juiz, descrita na sessão anterior. A juíza define a situação com as seguintes palavras:

Você está sozinha e é a mais fraca. Esquece da sua vida. O que vai ser dessa criança se já está sem pai e se você for encontrada morta, ele vai para um orfanato. Estou alertando a senhora que a justiça não tem como protegê-la cem por cento. Eu estou preocupada com seu amanhã e com essa criança envolvida, pois não quero que ela vá para o abrigo.

A declaração de falta de proteção estatal mistura-se aqui com construtos sociais de gênero (lógica naturalizada nas relações familiares e na essencialização do feminino), já que é negada à mulher a condição de sujeito de direito, ela é reduzida à sua condição de mãe. Em um determinado momento da audiência, as questões de "violência doméstica e familiar contra a mulher" são relativamente apagadas, e as de ordem familiar ganham maior espaço. O que foi reforçado quando, ao fim da audiência, a medida protetiva foi de certo modo suspensa, para que André pudesse participar do ritual cristão da primeira comunhão do filho.

Sabemos que as/os magistradas/os, enquanto representantes das instituições judiciárias, ocupam um lugar legitimado socialmente como sujeitos que detêm a autoridade de lidar com os conflitos sociais. Estas relações de saber e poder acompanham as dinâmicas de atendimento e podem ser pensadas como uma prática arbitral, pois a lógica com que esta juíza opera é

\footnotetext{
21 DEBERT, 2006.
}

${ }^{22}$ É importante contextualizar que, nesse caso específico, a mulher inicialmente posicionara-se contrária ao prosseguimento do processo penal e o acusado reivindicava seu direito de visitar o filho. 
definir modos de agir para as/os envolvidas/os no processo, sobretudo as mulheres, a fim de assegurar a continuidade do mesmo. Esta direção singulariza o funcionamento das audiências da magistrada. Assim, parece-nos prevalecer uma prática arbitral, na medida em que a juíza instrui, determina, o que as mulheres e os homens devem fazer.

\section{Estilo reparação moral}

Prosseguindo na descrição de audiências de ratificação conduzidas por "estilos" e lógicas singulares, conforme as concepções das/os magistradas/os que as conduzem, passamos a descrever um terceiro tipo de práticas recorrentes observadas na Vara pesquisada.

Em algumas das sessões das audiências um outro juiz iniciava dizendo às mulheres: "Olha, essa audiência é para saber se você quer continuar. Se você continuar, vamos colher provas, ouvir testemunhas, aí no final ele pode ser preso ou absolvido". A mediação entre as partes era uma das características da prática desse magistrado, e esse aspecto talvez se deva à sua trajetória profissional pois, na época da pesquisa, trabalhava em um dos projetos de mediação de conflitos do Judiciário. Os encaminhamentos que este juiz dava às audiências de ratificação poderiam ser chamados de "reparação moral". Explicamos este ponto destacando um processo que chamou nossa atenção por ser um dos raros casos em que a vítima era uma mulher negra e no qual surgiu uma figura jurídica singular que é o "perdão judicial". ${ }^{23}$

Na audiência em pauta, o juiz informou às partes o significado do rito que estava sendo iniciado. Ao lado direito da mesa estava Diana, uma jovem mulher negra, cabisbaixa, a seu lado sua advogada, branca, ao lado esquerdo, o advogado do acusado e, em outra mesa, à frente, o juiz e seu estagiário no computador, todos homens e brancos. A mãe de Diana estava sentada atrás do espaço ocupado pelo advogado. Vale destacar que Diana tinha uma relação afetivo-amorosa com o acusado, sem coabitação, que ela já havia registrado quatro $\mathrm{BOs}$ contra ele, incluindo ameaça de morte e cárcere privado, havendo já uma medida protetiva deferida. Após a indagação inicial, Diana permanece de cabeça baixa e em silêncio. $O$ juiz explica que se trata de uma audiência de ratificação, que tem a intenção de definir se o processo penal será instaurado. ${ }^{24}$

\footnotetext{
Juiz: A senhora solicitou medida protetiva para ele não se aproximar de você, não é? Ela não responde e começa a chorar.

Juiz: Por que a senhora está chorando?

Diana não fala, continua a chorar cabisbaixa.

Juiz: A audiência de hoje é muito simples. Basta a senhora dizer se quer ou não continuar. Só depende da senhora.

Ela continua chorando, sem nada dizer.

O advogado dele fala: Ele pode se retratar para você [olhando para o juiz].

Juiz: Se você não der continuidade ao processo, não perde direito nenhum. Quer dar uma chance a ele? Quer continuar com o processo ou dar um perdão judicial? Advogado: Eu assumo o compromisso de que ele não vai fazer isso novamente. Ele está no andar abaixo; posso chamá-lo para que peça desculpas e paramos por

${ }^{23}$ Questão tratada em detalhe em trabalho de um dos autores deste artigo, apresentado no $36^{\circ}$ Encontro

${ }^{24}$ É importante citar que, em 2009, a Terceira Seção do STJ decide que não é necessário coabitação para caracterização da violência doméstica contra a mulher. De acordo com o documento, "o namoro evidencia uma relação íntima de afeto que independe de coabitação. Portanto, agressões e ameaças de namorado contra a namorada - mesmo que o relacionamento tenha terminado, mas que ocorram em decorrência
} Anual da Anpocs (RIFIOTIS, 2012). dele-caracterizam violência doméstica". 
aqui, para você não se incomodar mais?

A mãe de Diana interrompe o diálogo e diz: Minha filha, tu queres passar por isso novamente?

Diana sem nada dizer permanece cabisbaixa a chorar continuamente.

O advogado segue: $A$ senhora pode ficar aí na porta ao lado [apontou para a porta à direita do Ministério Público], e eu o chamo para ele se retratar a ele [referindo-se ao juiz]. A advogada olha para ela e diz: Se você quiser retirar.

Juiz: Você é quem sabe se quer continuar com o processo e se incomodar na Justiça.

No mesmo instante a advogada comenta: "Você quer continuar a se incomodar vindo nas outras audiências? Esse ato é perdoável ou imperdoável?" Na sequência, o advogado sugere que o acusado entre na audiência e peça o perdão.

No desfecho da audiência tem-se inúmeras vezes a repetição da fala do advogado do acusado e do juiz com os mesmos argumentos, todos direcionados a Diana. Após alguns minutos de silêncio, ela com a voz trêmula em meio a muitas lágrimas diz: "Só não quero mais vê-lo". Imediatamente o juiz ordena ao advogado para chamar o acusado, explicitando: "Então o chame aqui para dar o perdão judicial e não terá que vê-lo mais". Minutos depois, o advogado retorna com um jovem de pele e cabelos claros, que se senta na frente de Diana e fala em tom brando, olhando para baixo: "Eu quero pedir perdão, me arrependo do que fiz". O juiz imediatamente olha para Diana e solicita sua decisão, e ela continua a chorar sem nada dizer. Após alguns minutos em silêncio e todos olhando para ela, Diana não menciona nenhuma palavra, mas confirma com a cabeça. Essa expressão foi suficiente para o juiz dar continuidade e entender que o processo estava encerrado. Na sequência, recomenda ao acusado que se afaste de Diana e ainda indaga: "Você promete que não vai mais incomodar ela?" O rapaz não responde e volta a ficar cabisbaixo. No mesmo instante o advogado diz: "Ele moralmente se compromete que não vai se aproximar dela. Ele é de uma família renomada e não vai envergonhar a sua família. Eu o conheço desde pequeno, e sei do seu erro, por isso estou fazendo ele pedir perdão".

No diálogo com as/os operadoras/es do direito acerca do "perdão judicial", surgiram algumas justificativas sobre esse encaminhamento. A primeira diz respeito ao poder discricionário do juiz na escolha das providências que poderá adotar, mediante determinada situação regulamentada pela Lei. A segunda refere-se a sua escolha pela prescrição do "perdão judicial", e outros artigos do Código Penal, já que a Lei 11.340 é ordinária e possibilita esses códigos aplicativos. ${ }^{25}$

A utilização desse instrumento jurídico é possível, na medida em que a LPM é uma Lei Ordinária Complementar ao Código Penal, ou seja, utiliza outras normativas para encaminhar os processos. Tendo em vista, portanto, a complexidade que o sistema legal representa, cabe situar como certas ideias são incorporadas e distribuídas nos processos encaminhados pela LMP. Segundo Leonardo Augusto de Almeida Aguiar, ${ }^{26} \mathrm{O}$ "perdão judicial" está previsto no Código Penal e enseja o reconhecimento da extinção de punibilidade, que só cabe na hipótese de ação penal privada. Trata-se de um tema bastante amplo e diverso, variando entre, de um lado, análises da definição do "perdão judicial" e, de outro, o modo como cada abordagem compreende a sua natureza jurídica.

\footnotetext{
${ }^{25}$ Segundo as/os operadoras/es do direito, as referências são feitas fundamentalmente aos artigos: 120 do Código Penal, sobre o "perdão judicial"; 103, relacionado à decadência do direito de queixa ou de representação; 104, 105 e 106, relativos à renúncia expressa ou tácita do direito do perdão do ofendido; 107 , que descreve as possibilidades de extinção da punibilidade, referidas especialmente nos incisos V, VI, VII (revogado pela Lei n.11.106.2005) e IX (BRASIL, 1940).

${ }^{26}$ Leonardo Augusto de Almeida AGUIAR, 2004.
} 
Pensamos que o uso do "perdão judicial" pode estar atrelado ao afunilamento das ações penais, e que sua aplicação contraria as prescrições legais descritas na LMP, mais precisamente do artigo 41, onde está expressa a exclusão dos ritos da Lei 9.099/95 para os encaminhamentos dos processos envolvendo "violência doméstica e familiar". Anulando a margem para a mediação do conflito anteriormente possibilitada pela Lei 9099/95 para casos de "pequeno potencial ofensivo". Ainda vale considerar que as críticas feministas sobre os modelos conciliatórios de casais em situação de "violência conjugal" tiveram reflexos no destaque dado nesse artigo da LMP, que deixa de considerar a "lesão corporal leve" como sendo "de pequeno potencial ofensivo", instituindo o aumento da pena com três meses a três anos de detenção, se a lesão for praticada contra ascendente, descendente, irmão, cônjuge ou companheiro. Assim, a utilização desse instrumento, "perdão judicial", está em pleno desacordo com as reivindicações feministas na promulgação da Lei 11.340/2006.

É importante sublinhar, para fins de análise, que os discursos do juiz e da advogada durante a audiência revelam o lugar que as práticas e os saberes compõem no campo de aplicação e efetividade da Lei: "Você é quem sabe, quer continuar com o processo e se incomodar na Justiça?" - pergunta do juiz. "Você quer continuar a se incomodar vindo nas outras audiências? Esse ato é perdoável ou imperdoável?" - perguntas da advogada. De certo modo, o perdão talvez seja a palavra recorrente nas audiências.

Registramos inúmeras audiências onde o perdão foi reiterado, inclusive na prática de outras/os magistradas/os. Isto é, nem sempre dizia respeito ao "perdão judicial" pautado no dispositivo jurídico, mas sim ao ato de perdoar. Essa retórica traduz uma prática jurídica local, marcada, especificamente na pesquisa realizada, na maior parte das vezes em que os/as advogados/as percebem que a mulher que vai se pronunciar está em dúvida se deve ou não ser favorável ao ajuizamento do processo penal, pela pergunta: "Você quer perdoá-lo?" Vale registrar que o "perdão judicial" estava presente na audiência, sem que o mesmo tenha sido referendado no termo da audiência. ${ }^{27}$ Os assessores do magistrado, após questionamentos, explicaram que a escolha da expressão "perdão judicial" é orientada pelo Código Penal, no entanto, ela é utilizada na audiência por ser uma linguagem acessível e facilitar a compreensão das mulheres na decisão de instaurar, ou não, o processo penal. Aqui interessa saber o que significa a escolha do emprego do termo "perdão judicial" e os pressupostos que orientam essas práticas. De um lado, há um esforço de pensar sobre o modo como essa noção está sendo traduzida pelas/os operadoras/es do direito no campo da intervenção e, de outro, a reflexão incide sobre os limites dessa noção e sua rentabilidade nas audiências.

A cena etnográfica descrita revela que o perdão é atribuído ao juiz, pois o acusado e seu advogado remetem-se ao magistrado para solicitar o perdão, que formaliza a anuência da mulher. Nesse caso, o juiz precisa de sua anuência, pois nessa audiência de ratificação é ela quem escolhe, mediada pelos magistrados, se irá permanecer ou não com o processo na justiça criminal. Pode-se pensar que o perdão é considerado uma expressão que remete à compaixão como um valor moral. Se tal relação, que precisa ser aprofundada, for válida, o perdão seria operacionalizado como uma atitude motivada pela compaixão e mediada por uma construção moral. ${ }^{28}$

\footnotetext{
${ }^{27}$ Documento legal produzido no fim de cada audiência e que se junta ao processo.

${ }^{28}$ O perdão, nesse caso, parece-nos uma estratégia política para a resolução e as negociações humanas e, apesar de em sua origem pertencer à linguagem religiosa, não se restringe a esse âmbito. Segundo Hannah ARENDT (2001), o perdão corresponde a uma diminuição dos julgamentos com relação ao outro que ofendeu, pois permite a ausência de acusação. Poderíamos aqui referir a uma economia moral, nos termos de Didier FASSIN (2010), como discutido no texto de RIFIOTIS (2014a).
} 
As narrativas do advogado do acusado, em diversos momentos da audiência referida no texto, mostram suas concepções morais, socioeconômicas e de família: "Você sabe que a família dele é uma família reconhecida aqui, e que todos são gente boa. [...] Ele é de uma família renomada e não vai envergonhar a sua família". Estes discursos parecem dignos de nota, pois revelam um regime de classificação dos arranjos familiares, claramente exposto na valoração da família de camadas médias e, por conseguinte, evidencia-se o risco, enunciado por Debert e Gregori, ${ }^{29}$ da transformação da defesa das mulheres em defesa da família e, aqui, da família de determinada classe e etnia. Nesse sentido, Debert e Beraldo de Oliveira ${ }^{30}$ indicam algumas questões a serem investigadas, mais especificamente se na atuação dos juízes, as mulheres são reconhecidas como sujeitos de direitos, e se nesse espaço ainda deverão ser tratadas de acordo com ideais familiares, concordantes com determinados preceitos morais.

Não é demais reparar que os processos de produção da verdade judiciária em relação à LPM revelam, por meio de expressões religiosas - o perdão de Diana, a confissão e o arrepender-se do acusado -, uma lógica subjacente às práticas judiciárias observadas na pesquisa. O "perdão judicial" seria uma espécie de reparação de insultos morais de alguns atos violentos. Por que o perdão é evocado, nos casos em que a "violência" é tipificada como lesão corporal leve, difamação, injúria, ameaças e ofensas? Tal quadro remete-nos à existência de uma prática institucional de reparação de insultos morais. ${ }^{31}$ No entanto, observamos na pesquisa empírica que o "perdão judicial" é uma estratégia de interrupção da continuidade dos procedimentos jurídicos no próprio âmbito da Vara Criminal, aliada à dimensão moral, que de certa forma é velada nos discursos das/dos operadoras/es do direito, ao fazerem uso dos códigos legais. ${ }^{32}$ Assim, parece-nos que a "violência" está sendo transformada em insulto, atrelado à dimensão moral, e passa a ser mediada nas audiências de ratificação pelas/os operadoras/es do direito, as/os quais se utilizam de técnicas de pacificação, através do instrumento do "perdão judicial".

\section{Considerações finais}

Ao identificar as diferentes facetas do trabalho na Vara Criminal onde foi realizada a pesquisa entre 2008 e 2010, escolhemos inventariar/descrever o modo como os/as juízes/as realizavam as audiências de ratificação nos casos tipificados pela Lei 11.340/2006. Cada audiência de ratificação expressa uma singularidade própria de um modo de produção de justiça no campo da "violência de gênero", o qual ganha forma a partir da maneira particular com que cada juiz/juíza avalia cada processo e opera naquelas audiências. O que nos coloca frente à autonomia dos/as juízes/as no encaminhamento dos processos.

Certamente a autonomia no trabalho dos/as juízes/as é importante para que possam ter uma avaliação específica da complexidade dos casos reduzida pelo e no processo de tradução operado desde o BO na DEAM, resultando na chamada redução a termo. No campo da antropologia jurídica, encontramos uma abordagem que pode orientar a reflexão sobre a produção de justiça no Brasil. Referimo-nos ao trabalho de doutorado de Regina Lúcia Teixeira Mendes da Fonseca, o qual trata das representações de juízes brasileiros sobre o princípio do livre convencimento motivado e da "hegemonia do 'dizer o direito'" que eles exercem. ${ }^{33}$

\footnotetext{
29 DEBERT \& GREGORI, 2008.

${ }^{30}$ DEBERT E BERALDO DE OLIVEIRA, 2007.

31 Luís Roberto CARDOSO DE OLIVEIRA, 2008.

${ }^{32}$ Wânia PASINATO, 2010.

${ }^{33}$ Regina Lúcia Teixeira Mendes da FONSECA, 2008, p. 26.
} 
Num contexto em que "dizer o direito", que seria uma prerrogativa do legislador e parece tender a ser ocupada pelos/as magistrados/as, precisamos problematizar a judicialização das relações sociais de um modo crítico. Conscientes de que estamos num campo atravessado por disputas políticas, não podemos deixar de explicitar que não estamos propondo uma crítica à Lei 1 1.340/2006, mas dos modos como ela vem operando, que nos mostram seus limites e suas ambiguidades, indicando-nos que ajudicialização é uma "solução-problema". ${ }^{34}$ Evidentemente, não se trata aqui de defendermos ingenuamente uma espécie de neutralidade da justiça, mas de colocar em questão as formas como atuam os atravessamentos morais e políticos das/os operadoras/es do direito.

Assim, retomando os resultados da pesquisa que estamos apresentando, acreditamos ter evidenciado que o modo como cada magistrado/a concebia as assimetrias de gênero e o lugar que as mulheres e os homens deveriam ocupar nas relações familiares, foi determinante na condução dos processos. A própria causa, ao menos nas audiências de ratificação, tornava-se, por vezes, um objeto secundário. Em tal contexto e frente aos resultados da pesquisa, a pergunta que nos colocamos poderia ser formulada nos seguintes termos: "Quais os limites e as implicações da autonomia dos/as juízes/as e quais as suas implicações na produção da justiça no campo da "violência de gênero?"

O essencialismo nas concepções de mulher e homem e a defesa da organização de papéis sexuais hegemônicos são duas marcas importantes e mesmo determinantes no resultado dos processos nos casos analisados. Assim, mais do que diferentes "estilos" dos/ as magistrados/as, o que a pesquisa mostrou foi que o propósito da pergunta inicial, realizada nas audiências de ratificação sobre o interesse na continuidade do processo, era abrir a possibilidade para uma direção própria a cada magistrado/a, sem que a resposta dada pela vítima fosse o elemento efetivamente considerado.

A própria causa algumas vezes era deixada para um segundo plano, quando se focava a representação da mulher e do homem atrelada ao desempenho dos papéis materno e paterno, por exemplo. Casos de "violência doméstica e familiar" contra a mulher foram, por vezes, reduzidos a questões de parentalidade e a outras questões morais, ficando em segundo plano o móvel que originou a própria audiência. Da mesma forma, o processamento jurídico revela suas ambiguidades, reproduzindo assimetrias de gênero no próprio âmbito de um julgamento realizado no quadro da LMP, e reduzindo os atores envolvidos a papéis sociais atrelados à maternidade e à paternidade, reforçando polaridades de gênero.

Porém, isso não ocorre de modo homogêneo e linear. A pesquisa mostrou que há disputas no próprio campo que merecem ser destacadas. Os modos de conduzir as audiências de ratificação, próprios a cada juiz/a, levam a que os processos tomem rumos bastante variados, sobretudo pela relação que estabelecem com mulheres e acusados.

Nesta perspectiva, entendemos que as intervenções políticas e sociais, realizadas no âmbito da Vara Criminal que foi nosso locus de estudo, eram organizadas não só a partir de fatores estruturais, mas também das trajetórias individuais/subjetivas no plano das experiências profissionais e políticas, das suas concepções morais e do lugar institucional/ social que cada magistrado/a ocupava. Dessa maneira, a aplicação da LMP era produzida a partir de condições subjetivas e relacionais.

As práticas observadas, em relação às demandas que chegavam àquela Vara Criminal, não se limitaram ao âmbito criminal e punitivo, mas se inseriram em moralidades traduzidas por posicionamentos diversos e ambíguos. Essa lógica parece ser um tanto controversa, principalmente porque na contemporaneidade, com a crescente judicialização das relações sociais, a sociedade tem apostado cada vez mais no sistema jurídico. ${ }^{35}$

${ }^{34}$ RIFIOTIS, 2008, p. 230

${ }^{35}$ RIFIOTIS, 2004 e 2008.

614 Estudos Feministas, Florianópolis, 23(2): 601-617, maio-agosto/2015 
Dessa forma, o arquivamento ou não de um processo dependia do "estilo" de cada magistrado/a. Algumas vezes, o juiz, ou a juíza, adotava uma prática que consideramos como tutelar, onde parecia atribuir às mulheres aspectos de passividade e fragilidade; outras vezes, buscava direcionar o modo como mulheres e homens deviam operar nas relações familiares, evidenciando uma prática marcada pelo que caracterizamos como estilo arbitral (pedagógico e mediador); e ainda, em outro tipo de conduta, a/o magistrado/ a apresentava uma prática que se caracterizava pela mediação e pela reparação moral.

Em resumo, a pesquisa mostrou como os/as magistrados/as, nas audiências de ratificação no período da pesquisa, não apenas aplicavam a LMP e o Código Penal, mas o faziam guiados por valores morais e políticos, demonstrando que o Judiciário nem sempre atuava dentro das expectativas implicadas na LMP. Há, portanto, uma significativa convergência entre o campo moral e o jurídico. Essa questão pode ser visualizada nas margens elásticas de interpretação da LMP, das quais sobressaem especialmente a valoração da família, deixando perceber que a tradução dos casos de "violência doméstica e familiar contra a mulher" não se esgota nos seus enunciados legais e deve ser permanentemente monitorada.

\section{Referências}

AGUIAR, Leonardo Augusto de Almeida. Perdão judicial. Belo Horizonte: Del Rei, 2004.

ARDAILLON, Danielle; DEBERT, Guita Grin. Quando a vítima é mulher: análise de julgamento de crimes de estupro, espancamento e homicídios. Brasília: Conselho Nacional dos Direitos da Mulher, 1987.

ARENDT, Hannah. A condição humana. Tradução Roberto Raposo. Rio de Janeiro: Editora Forense Universitária, 2001.

BANDEIRA, Lourdes; SUÁREZ, Mireya (Org.). Violência, gênero e crimes no Distrito Federal. Brasília: Editora UNB, 1999.

BLAY, Eva Alterman. Assassinato de mulheres e direitos humanos. São Paulo: Editora 34, 2008.

BRAGAGNOLO, Regina. Experiências e lições em uma vara criminal e juizado de violência doméstica e familiar contra a mulher em Santa Catarina. 2012. Tese (Doutorado em Psicologia) - Programa de Pós-Graduação em Psicologia, Universidade Federal de Santa Catarina, Florianópolis, 2012.

BRASIL. Decreto-Lei n².848, de 7 de dezembro de 1940. Cdigo Penal. Rio de Janeiro, 1940. Disponível em: http://www.planalto.gov.br/ccivil_03/decreto-lei/del2848compilado.htm. Acesso em: 12 maio 2013.

Presidência da República. Lei 9.099 de 26 de setembro de 1995. Dispõe sobre os Juizados Especiais Cíveis e Criminais e dá outras providências. Disponível em: http:// www.planalto.gov.br/ccivil_03/leis/19099.htm. Acesso em: 14 maio 2013.

. Lei $n^{\circ} 11.340$, de 7 de agosto de 2006. Cria mecanismos para coibir a violência doméstica e familiar contra a mulher... Disponível em: http://www.planalto.gov.br/ ccivil_03/_ato2004-2006/2006/lei/l1 1340.htm. Acesso em: 20 maio 2014.

CAMPOS, Carmen Hein de (Org.). Lei Maria da Penha comentada em uma perspectiva jurídico-feminista. Rio de Janeiro: Lumen Juris, 2011.

CARDOSO DE OLIVEIRA, Luís Roberto. "Existe violência sem agressão moral?" Revista Brasileira de Ciências Sociais, v. 23, n. 67, p. 135-146, jun. 2008.

CORRÊA, Mariza. Morte em família: representações jurídicas de papéis sexuais. Rio de Janeiro: Graal, 1983

Os crimes da paixão. São Paulo: Editora Brasiliense, 1981. 
DEBERT, Guita Grin. "A família e as novas políticas sociais no contexto brasileiro". Interseções, Rio de Janeiro, UERJ, v. 3, n. 2, p. 71-92, 2001.

. "As Delegacias de Defesa da Mulher: judicialização das relações sociais ou politização da justiça?". In: CORRÊA, Mariza; SOUZA; Érica Renata de (Org.). Vida em família: uma perspectiva comparativa sobre 'crimes de honra'. Campinas: Pagu-Núcleo de Estudos de Gênero/Universidade Estadual de Campinas, 2006. p. 16-38.

DEBERT, Guita Grin; BERALDO DE OLIVEIRA, Marcella. "Os modelos conciliatórios de solução de conflitos e a 'violência doméstica'”. Cadernos Pagu, Campinas, n. 29, p. 305-337, jul./dez. 2007.

DEBERT, Guita Grin; GREGORI, Maria Filomena. "Violência e gênero: novas propostas, velhos dilemas." Revista Brasileira de Ciências Sociais, v. 23, n. 66, p. 165-185, fev. 2008.

FASSIN, Didier. La raison humanitaire. Une histoire morale du temps present. Paris: Gallimard/ Seuil, 2010.

FONSECA, Regina Lúcia Teixeira Mendes da. Dilemas da decisão judicial. As representações de juízes brasileiros sobre o princípio do livre convencimento motivado. 2008. 266 f. Tese (Doutorado em Direito) - Universidade Gama Filho, Rio de Janeiro, 2008.

GOMES, Márcia Queiroz de C.; TAVARES, Márcia Santana; SARDENBERG, Cecília Bacellar. "A aplicação da Lei Maria da Penha em foco. Cadernos Observe. Salvador: NEIM/UFBA, 2010. v. 1.

GREGORI, Maria Filomena. Cenas e queixas: um estudo sobre mulheres, relações violentas e a prática feminista. Rio de Janeiro: Paz e Terra, 1993.

GROSSI, Miriam Pillar. "Rimando amor e dor: reflexões sobre a violência no vínculo afetivoconjugal". In: PEDRO, Joana Maria; GROSSI, Miriam Pillar (Org.). Masculino, feminino, plural: gênero na interdisciplinaridade. Florianópolis: Editora Mulheres, 2006. p. 293-313.

GROSSI, Miriam Pillar; TEIXEIRA, Analba Brazão (Org.). Histórias para contar: retrato da violência física e sexual contra o sexo feminino na cidade de Natal. Natal/Florianópolis: Casa Renascer/NIGS-PPGAS/UFSC, 2000.

GROSSI, Miriam Pillar; MINELLA, Luzinete Simões; LOSSO, Juliana Cavilha Mendes. Gênero e violência: pesquisas acadêmicas brasileiras (1975-2005). Florianópolis: Editora Mulheres, 2006.

HERMANN, Jacqueline; BARSTED, Leila Linhares. O Judiciário e a ordem legal e a (des)ordem familiar. Rio de Janeiro: Cepia, 1995.

HARAWAY, Donna. "O humano numa paisagem pós-humanista". Tradução de Marcos Santarrita. Revista Estudos Feministas, Rio de Janeiro: CIEC/UFRJ, ano 1, n. 2, p. 277-292, 1993.

LAGO, Mara Coelho de Souza. "De sujeitos e identidades: diálogos entre Ciências Humanas e Psicanlise. In: RIAL, Carmen Sílvia Moraes; TONELI, Maria Juracy Filgueiras (Org.). Genealogias do silêncio: feminismos e gênero. Florianópolis: Editora Mulheres, 2004. p. 73-78.

PASINATO, Wânia. "Avanços e obstáculos na implantação da Lei 1 1.340/2006". In: CAMPOS, Carmen Hein de (Org.). Lei Maria da Penha comentada em uma perspectiva jurídicofeminista. Rio de Janeiro: Lumen Juris, 2010. p. 119-142.

RINALDI, Alessandra de Andrade. "Violência e gênero. A construção da mulher como vítima e seus reflexos no Poder Judiciário: a Lei Maria da Penha como um caso exemplar". In: REUNIÃO BRASILEIRA DE ANTROPOLOGIA, 26, 4 jun. 2008. Trabalhos apresentados... Porto Seguro, 2008.

RIFIOTIS, Theophilos. "As delegacias especiais de proteção à mulher no Brasil e a judiciarização dos conflitos conjugais". Sociedade e Estado, UnB, Brasília, v. 19, n. 1, p. 85-119, 2004.

. "Judiciarização das relações sociais e estratégias de reconhecimento: repensando a 'violência conjugal' e a 'violência intrafamiliar'”. Revista Katálysis, Florianópolis, v. 11 , n. 2, p. 225-236, jul./dez. 2008.

616 Estudos Feministas, Florianópolis, 23(2): 601-617, maio-agosto/2015 
"Direitos Humanos e outros direitos: aporias sobre processos de judicialização e institucionalização de movimentos sociais". In: RIFIOTIS, Theophilos; HYRA, Tiago. Educação em Direitos Humanos. Discursos críticos e temas contemporâneos. 2. ed. revisada. Florianópolis: Editora da UFSC, 2011. p. 39-58.

"Direitos Humanos e Justiça: exercício moral e político no campo da violência de gênero". In: ENCONTRO ANUAL DA ANPOCS 36, 2012. Trabalhos apresentados... Águas de Lindoia: Anpocs, 2012.

. "Entre teoria, estética e moral: repensando os lugares da antropologia na agenda social da produção de justiça". Antropologia em primeira mão, n. 141, p. 5-24, 2014 a.

. "Judicialização dos direitos humanos, lutas por reconhecimento e políticas públicas no Brasil: configurações de sujeito". Revista de Antropologia, São Paulo, USP, v. 57, n. 1, p. 119-144, 2014b.

SAFFIOTI, Heleieth. Gênero, patriarcado, violência. São Paulo: Fundação Perseu Abramo, 2004.

[Recebido em 30 de janeiro de 2015 e aceito para publicação em 5 de fevereiro de 2015]

\begin{abstract}
A Study on Maria da Penha Law's Justice Production Modes in Santa Catarina
Abstract: This article aims to describe the practices in the criminal justice that are constructed based on law n. 11.340/2006 - known as Maria da Penha Law -, by male and female judges in charge of the execution of this legal provision in the Criminal Court and in the Gender Violence Court in the State of Santa Catarina. This is an ethnographic study based on interviews with law operators; field diaries constructed from observing trials; and documental analysis from legal processes. The research revealed that the usual practices of the law operators in the legal treatment of cases regarded as "domestic and family violence against the women" were conducted by the personal "styles" of each male/female judge when executing the ratification trials, typifying the means of communication and interactions based on moral values, characterized by different notions of gender, family and justice. The study of the practices of equalization and judgment highlighted that the modes of producing justice were linked to a moral dimension, veiled to a certain degree in the discourses of the law operators as they use the legal codes. The political positions of the law operators about the process of criminalization of the "domestic and family violence against women" resulted, many times, in practices that diverge from the expectations of the feminist movements regarding the sanctioning of Maria da Penha law, showing the importance of the debate of the judicialization of the social relations in the field of gender studies.
\end{abstract}

Key Words: Maria da Penha law; Law Operators; Justice; Gender Violence. 